\title{
EFFECT OF WORK HARDENING AND THERMAL STABILITY OF METAL CHIPS AFTER MACHINING ON PROPERTIES OF PLASTICALLY CONSOLIDATED PROFILES
}

\author{
Piotr NOGA, Adam ZWOLINSKI \\ AGH - University of Science and Technology, Faculty of Non-Ferrous Metals, Cracow, Poland, EU, \\ pionoga@agh.edu.pl, zwolo@agh.edu.pl
}

https://doi.org/10.37904/metal.2019.768

\begin{abstract}
Imposing large plastic deformation by SPD processes such as ECAP, HPT, ARB etc. in a relatively simple way enables to obtain material with high grain refinement. In result significant change in both strength and plastic properties can be observed. However, this hardening effect is highly thermal sensitive and even small increase in temperature can initiate structure recovery processes. In the following paper thermal stability of aluminum chips (AA1050, AA3103, AA5083) after machining has been examined. By identifying moment of structure recovery optimal conditions for plastic consolidation could be determined.
\end{abstract}

Keywords: Chips machining, hot extrusion, mechanical recycling

\section{INTRODUCTION}

One of the most important challenges facing Material Engineering has always been the improvement of the mechanical properties of metals and their alloys. Therefore, over the years, many techniques and methods have been developed to increase both the plasticity and strength of metallic materials [1-4]. Within less than 20 years, very popular became methods using the strong accumulation of deformation (Severe Plastic Deformation - SPD) which allowed to produce materials with improved strength properties. As a part of SPD methods, we can distinguish such processes as extrusion through an angular channel (ECAP) [5-8], highpressure torsion (HPT) [8-11], packet rolling (ARB) [6-8, 12] and many others.

Particular attention has been given to machining processes such as turning, milling etc. which allow to obtain materials with ultra-fine-grained (UFG) structure in a simple process. In contrast to the classic SPD methods during machining, it is possible to achieve plastic deformations of the order of 1 to 15 in just one pass [13] whereas, for example in ECAP, material deformation does not exceed 1.15 after one pass [14]. The tests carried out on alloy AA 6061 [15] confirmed possibility to achieve greater structure refinement during machining than in the case of ECAP.

The main disadvantage of machining process is high defragmentation of raw material, which forces the use of consolidation processes to obtain a solid material. This naturally involves raising the temperature, and thus can lead to unwanted structure restoration.

The purpose of this work is to determine the degree of material deformation during cutting and comparing the hardness of the obtained chips with material subjected to rolling process. Examinations allowed to determine also a temperature range for which the materials show thermal stability.

\section{EXPERIMENT}

The base materials for tests were three aluminum alloys (AA1050, AA3103 and AA5083) in the form of bars with a diameter of $40 \mathrm{~mm}$. The chemical composition of each material is given in Table 1. All profiles were subjected to turning process in order to obtain chips for further examinations. The machining was carried out at rotational speed of $310 \mathrm{rpm}$ and feed rate of $2 \mathrm{~mm} / \mathrm{s}$. To avoid contamination of the material, turning was carried out without the use of cooling emulsions. After machining chips were measured to evaluate their 
average size. Alloys in a form of chips were then subjected to thermal stability tests. For this purpose, a small sample of fragmented material was placed in the furnace and heated for $20 \mathrm{~min}$ in temperature range of $50{ }^{\circ} \mathrm{C}$ to $500{ }^{\circ} \mathrm{C}$. The annealed material was then subjected to hardness tests using a Shimadzu HMV-G microhardness tester with a load of $9.8 \mathrm{~N}$. Based on the obtained results, moment of the structural renewal for individual materials was determined. In the next stage of the research, the amount of deformation accumulated in the material after the cutting process was estimated. For this purpose, the raw material in the form of rods was milled into flat bars with dimensions of $3 \times 20 \times 150 \mathrm{~mm}$, and then rolled several times increasing each rolling reduction and measuring the hardness. From the obtained results, the HV diagram was drawn as a function of deformation $\varphi$. By comparing chips hardness after machining with the obtained curve, the amount of deformation accumulated in every material was estimated.

Table 1 Chemical composition of all examined materials (wt\%)

\begin{tabular}{|c|c|c|c|c|c|c|c|c|c|c|}
\hline Materiał & $\mathbf{S i}$ & $\mathbf{F e}$ & $\mathbf{C u}$ & $\mathbf{M n}$ & $\mathbf{M g}$ & $\mathbf{Z n}$ & $\mathbf{C r}$ & $\mathbf{N i}$ & $\mathrm{Ti}$ & $\mathbf{A l}$ \\
\hline AA1050 & $<0.1$ & 0.2 & 0.001 & $<0.01$ & 0.06 & 0.01 & 0.002 & - & - & balance \\
\hline AA3103 & 0.07 & 0.57 & 0.07 & 1.10 & 0.01 & - & - & - & 0.02 & balance \\
\hline AA5083 & 0.15 & 0.15 & 0.08 & 0.85 & 4.42 & 0.03 & 0.08 & - & 0.02 & balance \\
\hline
\end{tabular}

The last stage of research was determination of strength value that remained in the material after plastic consolidation. For this purpose, the sample weight of $25 \mathrm{~g}$ of every material was pressed on a hydraulic press under a pressure of $30 \mathrm{t}$. As a result, round billets with a diameter of $40 \mathrm{~mm}$ and height of $10 \mathrm{~mm}$ were obtained. Seven of these billets eventually constituted a charge for the extrusion process. The plastic consolidation was carried out at a temperature of $450^{\circ} \mathrm{C}$ with a ram speed of $0.5 \mathrm{~mm} / \mathrm{s}$. Material was preheated before extrusion for 20 minutes in order to achieve uniform heat distribution in billet. As a result, profiles with a $3 \times 15 \mathrm{~mm}$ rectangular cross section $(\lambda=25)$ were obtained from which specimens for hardness test were then cut.

\section{RESULTS AND DISCUSSION}

\section{Chips morphology}
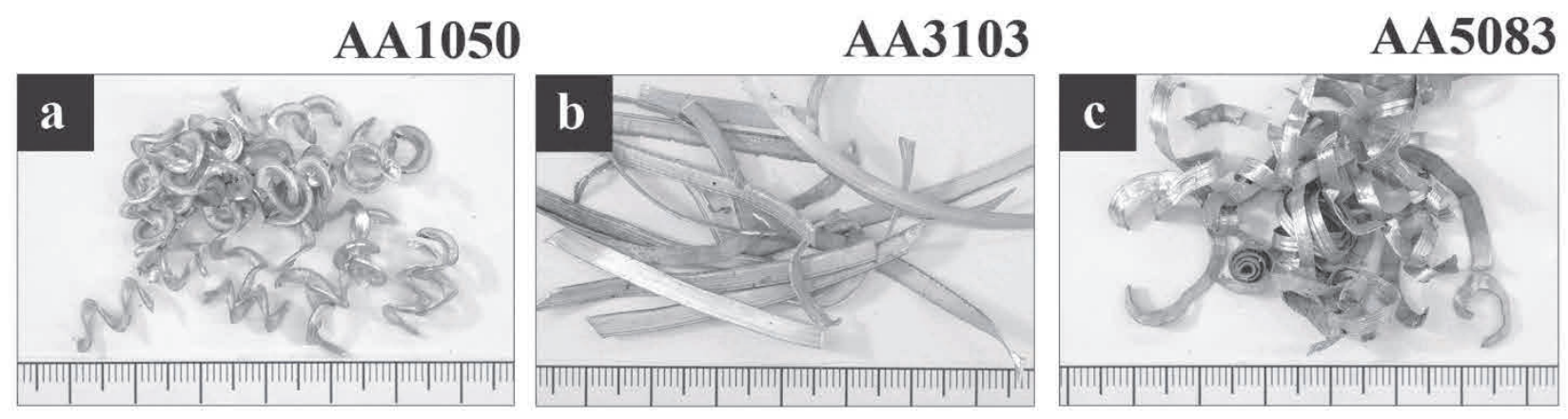

Figure 1 Chips morphology after machining process from a) AA1050; b) AA3103; c) AA5083 aluminum alloy

Photos of the chips after machining for each material are showed in Figure 1. It can be seen here that despite the same rolling conditions, both the shape and size of the chip differ significantly. In the case of AA1050 we deal with a strongly twisted material with a rough surface and an average length of $22 \mathrm{~mm}$. Chips from the AA3103 alloy were characterized by a smooth surface, slight entanglement and their length exceeding significantly more than $1 \mathrm{~m}$. For this reason, in order to facilitate further research, these chips were cut into equal lengths sections $(70 \mathrm{~mm})$. The waste after machining in the case of AA5083 showed intermediate features of two previous materials. These chips were slightly curved with a flat and smooth surface. Their average length was $10 \mathrm{~mm}$. The differences in the shape and size of the chips for these materials resulted 
directly from their chemical composition. The different proportion of individual elements in the alloy caused the formation of a different internal structure of the material which had a direct effect on the cutting conditions, such as cutting force or temperature. In work [16] authors examined influence of material structure on the cutting process of different materials. They determined the effect of second phase particles on chip breakage during turning. As a result of these studies, they divided aluminum alloys into three separate groups with various degree of fragmentation.

\section{Chips thermal stability}

The chips after the cutting process often have had a relatively high heterogeneity of deformation over their entire volume. Both the aforementioned chemical composition and cutting conditions have had significant influence on this differentiation. As result notable variation of hardness from the average value is visible. Among all examined materials, the biggest differences in measured HV values (Figure 2) showed AA5083 alloy.

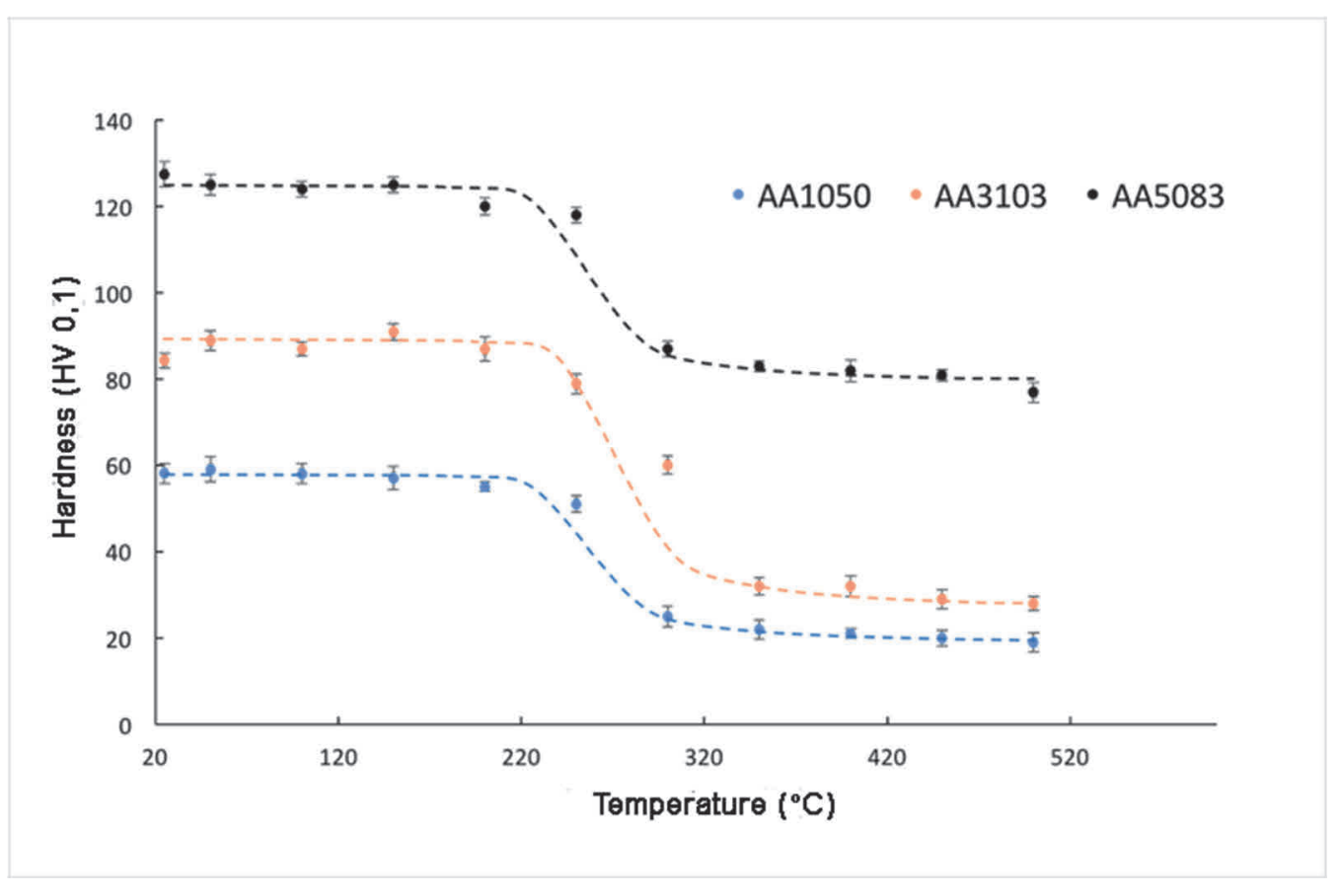

Figure 2 Chips hardness change as a function of annealing temperature

By analyzing the $\mathrm{HV}$ curve for AA1050, it can be noticed that up to approx. $200{ }^{\circ} \mathrm{C}$ the material maintains a constant hardness value equal to approx. $60 \mathrm{HV}$. After exceeding that temperature, the hardness gradually decreases up to the value of $\approx 20 \mathrm{HV}$. It results directly from the processes of recovery and simultaneous recrystallization of the material. At $400{ }^{\circ} \mathrm{C}$, the hardness stabilizes and the material returns to its base hardness. A similar three-step nature of the curves is also visible for two remaining alloys. In the case of AA3103, the initial hardness of the chip $(\approx 90 \mathrm{HV})$ is also kept at a constant level up to $200^{\circ} \mathrm{C}$, followed by a gradual decrease of $\mathrm{HV}$ with final stabilization at $400{ }^{\circ} \mathrm{C}$ on the level of $30 \mathrm{HV}$. As a result, heating process, the deformation strengthening from the turning process is completely removed from the material. Of all examined materials, AA5083 alloy chips showed the highest hardness value. It is both a result of strengthening during cutting and a significant addition of $\mathrm{Mg}(4.4 \mathrm{wt} \%)$ which additionally increases the hardness of this alloy. The average $\mathrm{HV}$ value of 125 units is maintained at a temperature up to $150^{\circ} \mathrm{C}$, followed by a slight drop in the range of $200-250{ }^{\circ} \mathrm{C}$ by about $5 \mathrm{HV}$. This relatively small drop may suggest the beginning of the internal structure renewal. A further increase of temperature to $300^{\circ} \mathrm{C}$ causes a strong decrease in hardness to $80 \mathrm{HV}$ 
and this value is maintained up to $500{ }^{\circ} \mathrm{C}$. In each of the above cases, exceeding the temperature of $350{ }^{\circ} \mathrm{C}$ results in return of material hardness back to the value before the cutting process. This information is particularly important in case of plastic consolidation, where the base material is often in the form of chips after machining process. Conducting extrusion at low temperature will retain strengthening within the profile. However, it should be remembered that, on the other hand, low temperature can lead to an increase in extrusion force and deterioration of extrudated quality (porous profile with a poor quality surface) [17].

\section{Magnitude of chips deformation}

The influence of rolling reduction on the hardness value for all materials was presented on Figure 3 . As can be seen in the case of AA1050 profile, the hardness after maximum rolling reduction $(\boldsymbol{\varphi}=1)$ has doubled $(40$ $\mathrm{HV}$ ) in comparison to HV of base material. Obtained approximation curve allowed to estimate the value of deformation in chips at about 4.6. This is the highest value of $\boldsymbol{\varphi}$ of all tested materials. A similar situation occurs in the case of alloy AA3103. Here again, the hardness value increased from the level of $35 \mathrm{HV}$ for the base material up to about $60 \mathrm{HV}$ for the maximum rolling reduction. The amount of strain accumulated in the chip was estimated at about 3.6. This is a relatively lower value in comparison to AA1050, and it may result from a small addition of $\mathrm{Mn}$. The last of examined materials which is AA5083 already in the initial state had a hardness exceeding the remaining materials with HV amount of 80 units. Further deformation as a result of rolling allowed to obtain a value of $140 \mathrm{HV}$ for maximum rolling reduction. The estimated deformation value for chips was only 0.6 . In case of this material, the addition of $\mathrm{Mg}(>4 \mathrm{wt} \%)$ significantly affected plasticity of the alloy, limiting process of strengthening during cutting process.

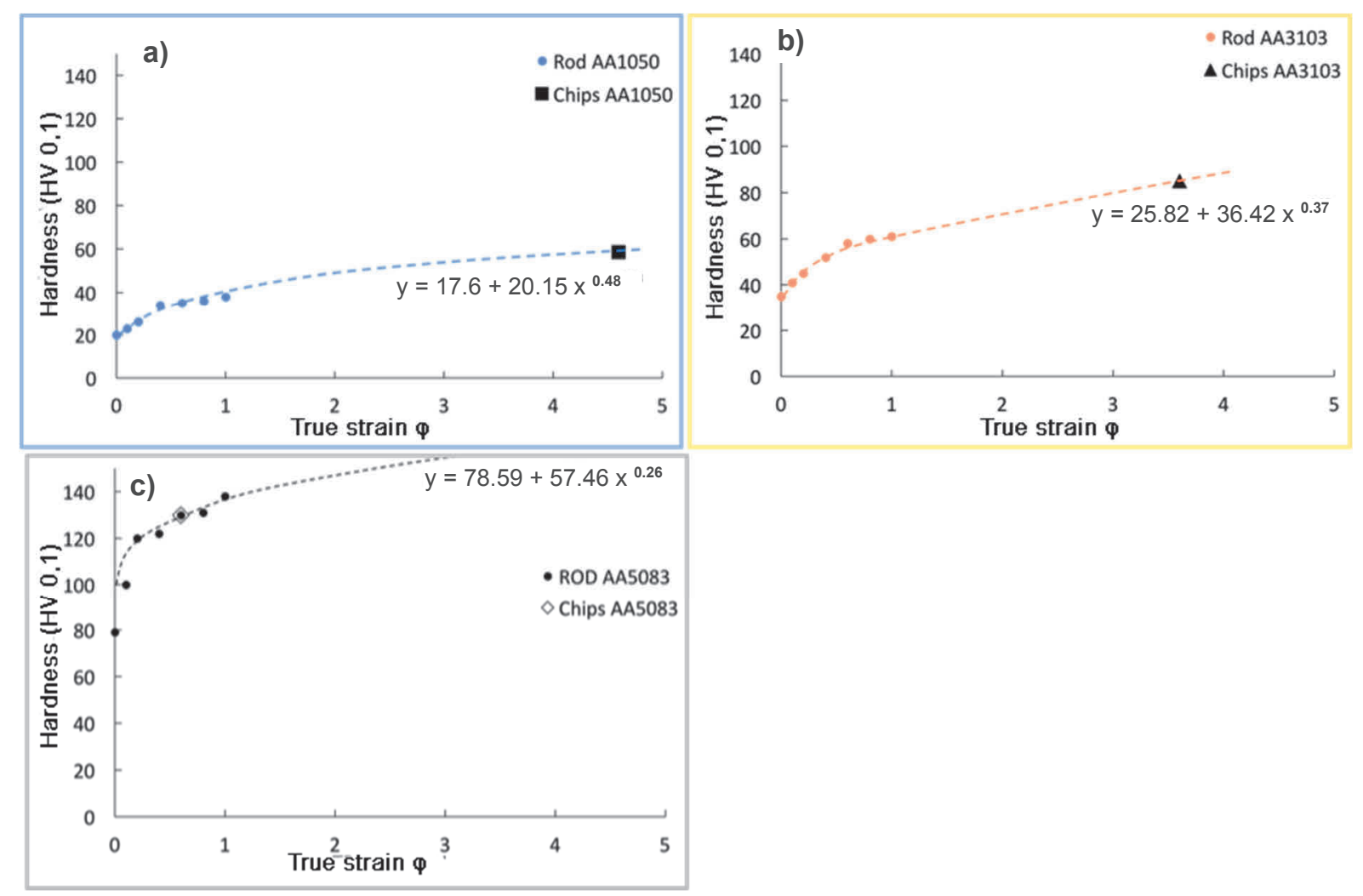

Figure 3 Hardness change as a function of rolling reduction for a) AA1050; b) AA3103; c) AA5083

It is worth mentioning that each rolled material showed a relatively smooth surface with no visible cracks at the edges. This indicates a reserve of plasticity that remained in the material even after deformation $\boldsymbol{\varphi}=1$. 


\section{Profiles hardness after plastic consolidation}

A hardness summary of consolidated profiles and chips after turning presents Table 2 . When comparing the hardness of the consolidated profiles with the base material, only small differences can be observed for AA1050 and AA3103 in favor of solid bonded profiles. This slight increase in HV can result directly from the residual deformation after turning. The oxide coating which breaks during the consolidation is also a natural strengthening component for the newly obtained flat bar.

Table 2 Hardness summary table for chips, initial and consolidated profiles for all examined materials (HV1)

\begin{tabular}{|c|c|c|c|}
\hline Material & Solid material & Chip after cutting & Profile \\
\hline AA1050 & 20.2 & 58.1 & 23.7 \\
\hline AA3103 & 34.6 & 84.4 & 37.9 \\
\hline AA5083 & 78.6 & 127.9 & 77.0 \\
\hline
\end{tabular}

\section{CONCLUSION}

- The tests carried out for the AA1050, AA3103, AA5083 alloys allowed to determine the starting point of materials recovery and recrystallization. It has been shown that all materials exhibit temperature stability between $150-200{ }^{\circ} \mathrm{C}$. Above that temperature, a slow decline of HV was noticed. Hardness curves above $350^{\circ} \mathrm{C}$ revealed stabilization of $\mathrm{HV}$ in each tested material.

- The highest deformation values were accumulated by chips produced from AA1050 and AA3103 alloys. They experienced 4.6 and 3.6 true strain value, respectively. The low level of strain for AA5083 can be explained by a significant addition of $\mathrm{Mg}$ in the alloy which limits its plasticity.

- $\quad$ The profiles after consolidation at $450^{\circ} \mathrm{C}$ obtained an $\mathrm{HV}$ value similar to the base material.

\section{ACKNOWLEDGEMENTS}

Financial support under grant no 16.16.180.006, is kindly acknowledged.

\section{REFERENCES}

[1] NOGA, P. and WIEWIORA, M. Structural features and mechanical properties of rapidly solidified AISi alloy. In METAL 2018: 27th International Conference on Metallurgy and Materials. Brno: TANGER, 2018, pp. 1660-1665.

[2] SKRZEKUT, T., KULA, A. and BLAZ, L. Structure evolution in annealed and hot deformed AIMg-CeO 2 composite. Key Engineering Materials. 2016. vol. 682, pp. 259-264.

[3] WLOCH, G., SKRZEKUT, T., SOBOTA, J., WOZNICKI, A. and BLAZ, L. Sliver matrix composite reinforced by aluminium-silver intermetallic phases. Archives of Metallurgy and Materials. 2017. vol. 62, pp. 427-434.

[4] SKRZEKUT, T. and BLAZ, L. Examination of aluminum matrix composites obtained by powder metalurgy and strenghtened by $\mathrm{AgO}$ and $\mathrm{CeO}_{2}$ particles. In METAL 2018: 27th International Conference on Metallurgy and Materials. Brno: TANGER, 2018, pp. 1722-1728.

[5] ROVEN, H.J., NESOBE, H., WERENSKIOLD, J.C. and SEIBERT, T. Mechanical properties of aluminium alloys processed by SPD: Comparison of different alloy systems and possible product areas. Materials Science and Engineering: A. 2005. vol. 410-411, pp. 426-429.

[6] CHERUKURI, B., NEDKOVA., T.S. and SRINIVASAN. R. A comparison of the properties of SPD-processed AA6061 by equal-channel angular pressing, multi-axial compressions/forgings and accumulative roll bonding. Materials Science and Engineering: A. 2005. vol. 410-411, pp. 394-397.

[7] MISIOLEK, W., HAASE, M., KHALIFA, N.B., TEKKAYA, A.E. and KLEINER, M. High quality extrudates from aluminum chips by new billet compaction and deformation routes. CRIP Annals-Manufacturing Technology. 2012. vol. 61 , pp. 239-242. 
[8] GRONOSTAJSKI, Z., SKUBISZEWSKI, T. and ZWIERZCHOWSKI, M. Deformation of aluminium bronze by HPT and ECAP methods. Journal of Machine Engineering. 2014. vol. 14, pp. 18-28.

[9] DASA, M., DASA, G., GHOSHA, M., WEGNERB, M., RAJNIKANTA, V., GHOSHCHOWDHURY, S. and PAL, T.K. Microstructure and mechanical properties of HPT processed $6063 \mathrm{Al}$ alloy. Materials Science and Engineering: A. 2012. vol. 558, pp. 525-532.

[10] VAFAEI, R., TOROGHINEJAD, M.R. and PIPPAN, R. Evaluation of mechanical behavior of nano-grained 2024 Al alloy during high pressure torsion (HPT) process at various temperatures. Materials Science and Engineering: $A$. 2012. vol. 536, pp. 73-81.

[11] EIZADJOU, M., MANESH, H.D. and JANGHORBAN, K. Microstructures and mechanical properties of ultra-fine grains (UFGs) aluminum strips produced by ARB process. Journal of Alloys and Compounds. 2009. vol. 474, pp. 406-415.

[12] REZAEI, M.R., TOROGHINEJAD, M.R. and ASHRAFIZADEH, F. Effects of ARB and ageing process on mechanical properties and microstructure of 6061 aluminum alloy. Journal of Materials Processing Technology. 2011. vol. 211, pp. 1184-1190.

[13] SWAMINATHAN, S., SHANKAR, M.R., RAO, B.C., COMPTON, W.D., CHANDRASEKAR, S., KING, A.H. and TRUMBLE, K.P. Severe plastic deformation (SPD) and nanostructured materials by machining. Journal of Materials Science. 2007. vol.42, pp.1529-1541.

[14] GROZA, J.R. and SHACKELFORD, J.F. Materials Processing Handbook, CRC Press, 2007.

[15] SHANKAR, M.R., CHANDRASEKAR, S., COMPTON, W.D. and KING, A.H. Characteristics of aluminum 6061-T6 deformed to large plastic strains by machining. Materials Science and Engineering: A. 2005. vol. 410-411, pp. 364-368.

[16] KAMIYA, M. and YAKOU, T. Role of second-phase particles in chip breakability in aluminum alloys. International Journal of Machine Tools and Manufacture. 2008. vol. 48, pp. 688-697.

[17] WZOREK, L., WOLNIAK, R., LYP-WRONSKA, K., WIEWIORA, M., NOGA, P. and WZOREK, A. Analysis of product quality in the process of plastic consolidation of fragmented fractions of the AK11 alloy. Archives Metallurgy and Materials. 2018. vol. 63, pp. 667-672. 